\title{
PATTERNS OF ADULT-ONSET EPILEPSY ATTENDED IN AN EPILEPSY CLINIC IN A SPECIALISED HOSPITAL: A PROSPECTIVE CROSS SECTIONAL STUDY
}

\author{
SARDAR MH ${ }^{1}$, HOWLADER MAR ${ }^{2}$, MALLIK MU $^{3}$, APPOLO AM $^{4}$, ISLAM MS $^{5}$, AZAD KAK $^{6}$
}

\begin{abstract}
:
A prospective cross sectional study was designed to assess the patterns of adult-onset epilepsy and determine the types of epilepsy which develop after complex febrile convulsion (CFC) and find out the causes of epilepsy, from January to December 2008, in Epilepsy Clinic of the Department of Neurology of Bangabandhu Sheikh Mujib Medical University (BSMMU), Dhaka. 106 consecutive adult (age>13 years) patients with adult-onset epilepsy receiving treatment from Epilepsy Clinic of the Department of Neurology of BSMMU, Dhaka, were the sample of this study. Records of these patients were reviewed \& the patients \& their family members were interviewed to assess the medical history. The data obtained from the records and the interviews formed the basis of this study. Chi-Square test was applied to analysis the data. Interviewed results and records of 106 patients were analyzed. Of the 106 patients with adult- onset epilepsy, the epilepsy categories [median age: 20 years, range: 14-46 years] were: generalized epilepsies in 51 (54.06\%), partial epilepsies in 45 (47.7\%), \& undetermined epilepsies in 10 (10.6\%) Thirty one (32.86\%) of the 106 patients had history of CFC in the childhood $(71 \%$ male, 29\% female). Partial epilepsies were significantly associated with history of CFC [Odds Ratio: 3.29; (95\% CI 1.30-8.06), $\left.\left(c^{2}=5.49, d f=1, p=0.012\right)\right]$ when compared to other epilepsies and epilepsy syndromes. An initial unprovoked simple partial seizure was also significantly associated with a positive history of CFC lOdds Ratio: 8.05; (95\% CI 2.88-22.45), (c ${ }^{2}=15.86$, $d f=1, p<0.001)]$. Generalized epilepsies are more common than partial epilepsies. Partial epilepsies seem to be associated with a history of CFC in childhood. The mechanism \& pathophysiology of association between CFC and epilepsy in affected probands requires further investigations. Identification of the basic defect in relation to CFC \& epilepsy may have important implication for the prevention of adult- onset epilepsy in patients with history of CFC. But the risk of epilepsy after febrile convulsions is much less than reported in many hospital studies \& if febrile convulsion causes brain damage that leads to later epilepsy, this is a rare occurrence.
\end{abstract}

Keywords: Generalized epilepsy, partial epilepsy, febrile convulsion, afebrile seizures, genetic. J Dhaka Med Coll. 2011; 20(1) : 20-24.

\section{Introduction:}

Epilepsy is a common condition which we have to treat in different settings.For proper management of epilepsy we have to know the different catagories and causes of epilepsy.Children with febrile convulsions are at high risk of developing adult-onset epilepsy. Febrile convulsions occur in $2-5 \%$ of children. ${ }^{1,2}$ Hospital based studies have reported a high incidence of epilepsy in childhood after febrile convulsions upto $40 \% .{ }^{3}$ In contrast, population based studies suggest that the outcome is better, with incidence of $2 \%$ and $3.5 \%$ in two large American studies. ${ }^{4,5}$ Febrile convulsions may cause later afebrile seizures or some children may be predisposed to both febrile convulsions and subsequent afebrile seizers. ${ }^{6}$ The reported proportion of children with $\mathrm{CFC}$

1. Dr. Md. Hafiz Sardar, Assistant Professor of Medicine, Dhaka Medical College, Dhaka.

2. Dr. Md. Anisur Rahman Howlader, Assistant Professor of Medicine, Dhaka Medical College, Dhaka.

3. Dr. Md. Uzzwal Mallik, Indoor Medical Officer, Dhaka Medical College Hospital, Dhaka.

4. Dr. Al Mahmood Appolo, Assistant Registrar, Dhaka Medical College Hospital, Dhaka.

5. Dr. Mohammad Shaiful Islam, Registrar, Dhaka Medical College Hospital, Dhaka.

6. Prof. Khan Abul Kalam Azad, Professor of Medicine, Dhaka Medical College, Dhaka.

Correspondence: Dr. Md. Hafiz Sardar, 42/A, Indira Road, Flat-B4, Tejgaon, Dhaka, Cell Phone: +8801712269294, Email: drhafizsardar@yahoo.com 
who later developed epilepsy was between 2 and $7 \%$. A considerable number of patients may develop epilepsy after 16 years of age. ${ }^{8,9}$

Certain features of CFC may be predictive of a particular type of later epilepsy. Molecular genetic studies to date have found several loci for CFC on autosomal chromosomes. Partial seizures have also been linked to some regions of autosomal chromosomes. In the present study, we evaluated the association between history of CFC and adult-onset epilepsy and also a possible association between history of CFC and any specific type of epilepsy and epilepsy syndrome.

\section{Operational definitions:}

Febrile convulsion: An event in infancy or childhood associated with fever but without evidence of intracranial infection or defined cause. This is similar to the National Institutes of Health definition. ${ }^{10}$ Children with previous afebrile seizures were excluded. Suspected seizures in the first four weeks of life were excluded but convulsions during vaccination fever were included.

Simple febrile convulsion: A simple seizure with no focal features \& lasting less than 15 minutes in an infant $\&$ child with fever was defined as a simple febrile convulsion. Not complex.

Complex febrile convulsion: Longer than 15 minutes, focal or multiple (more than one convulsion per episode of fever). Febrile convulsion was defined as complex if the above criteria of simple febrile convulsion were not fulfilled. ${ }^{11}$

Recurrent febrile convulsion: More than one episode of convulsions associate $\mathrm{d}$ with fever.

Afebrile convulsion: Classification based on proposals of the International League Against Epilepsy. ${ }^{12}$ Children with more than one afebrile attack of seizure are defined as having epilepsy.

\section{Methods:}

This was a prospective cross sectional study with no therapeutic intervention or treatment. The research committee of Department of Neurology BSMMU had approved the study.
Written informed consent was obtained from all the patients aged 18 years $\&$ above $\&$ in case of patients aged $<18$ years, informed consent was obtained from authorized guardians.

The study subjects include 106 consecutive patients with adult-onset (e"13 years old) unprovoked seizures. Patients were recruited from Epilepsy Clinic of the Department of Neurology, BSMMU, Dhaka, from January to December 2008. Detailed history \& neurological examinations were done in all patients. The medical records, electroencephalograms (EEG) $\&$ the neuroimagings of the patients $\&$ medical records from Epilepsy Clinic of the Department of Neurology, BSMMU, Dhaka were reviewed \& details of their past $\&$ present illnesses were collected. The data regarding the $\mathrm{CFC}$ event was interviewed from the patients, parents $\&$ other relatives personally (no telephone interview).

The criteria proposed by the International Classification of Seizures \& Epilepsy \& Epilepsy Syndromes were considered while classifying the seizure type \& epilepsy \& epilepsy syndrome. ${ }^{13}$

The data were evaluated by Chi-square test and the Mantel Haenszel method was used to obtain the Odds ratios using SPSS Version 11.0. A p value of $<0.05$ was considered statistically significant.

\section{Results:}

Of the 106 patients with adult- onset epilepsy, the epilepsy categories [median age: 20 years, range: $14-46$ years] were: generalized epilepsies in 51 (54.06\%), partial epilepsies in $45(47.7 \%)$, \& undetermined epilepsies in 10 (10.6\%). 31 patients [22(71\%) male \& $9(29 \%)$ female; median age: 26 years, range: 14-46 years] had history of CFC in childhood. Partial epilepsies $(n=21)$ outnumbered generalized epilepsies $(n=9)$ in patients with history of $\mathrm{CFC}$; 27 patients had simple febrile convulsions $\& 4$ had complex febrile convulsions.

Positive history of CFC was seen significantly more in male than in female [Odd ratio: $2.70(95 \%$ CI $1.07-6.80),\left(\chi^{2}=3.63, \mathrm{df}=1\right.$, $\mathrm{p}=0.035)]$. Comparison between different groups of epilepsies showed a significant association 
Table-I

Patterns of adult-onset epilepsy

\begin{tabular}{lcc}
\hline $\begin{array}{l}\text { Number of patients with } \\
\text { generalized epilepsy }\end{array}$ & $\begin{array}{c}\text { Number of patients } \\
\text { with partial epilepsy } \\
\mathrm{N}=51\end{array}$ & $\begin{array}{c}\text { Number of patients with } \\
\text { undetermined type }\end{array}$ \\
\hline $54.06 \%$ & $47.7 \%$ & $\mathrm{~N}=10$ \\
\hline
\end{tabular}

Table-II

Adult-onset epilepsy who had febrile convulsions

\begin{tabular}{|c|c|c|c|c|c|}
\hline \multicolumn{3}{|c|}{$\begin{array}{l}\text { No. of patients who had history } \\
\text { of CFC in childhood } \\
\qquad N=92\end{array}$} & \multicolumn{3}{|c|}{$\begin{array}{l}\text { No. of patients who developed } \\
\text { epilepsy in adulthood } \\
\qquad \mathrm{N}=31\end{array}$} \\
\hline $\begin{array}{l}\text { Partial } \\
\text { epilepsy }\end{array}$ & $\begin{array}{l}\text { Generalized } \\
\text { epilepsy }\end{array}$ & Undetermined & $\begin{array}{l}\text { Partial } \\
\text { epilepsy }\end{array}$ & $\begin{array}{l}\text { Generalized } \\
\text { epilepsy }\end{array}$ & Undetermined \\
\hline 45(48.9\%) & $37(40.2 \%)$ & $10(10.9 \%)$ & 21(67.7\%) & $9(29 \%)$ & $1(3.3 \%)$ \\
\hline
\end{tabular}

between partial epilepsies \& a history of CFC [ Odds Ratio:3.24 (95\% CI 1.30-8.06), ( $c^{2}=5.49$, $\mathrm{df}=1, \mathrm{p}=0.012)]$. Similar association was also found between partial epilepsies $\&$ generalized epilepsies after excluding epilepsies in the undetermined category [Odd ratio: $0.37(95 \% \mathrm{CI}$ 0.04-0.95), $\left.\left(c^{2}=4.04, d f=1, p=0.039\right)\right]$. Age of onset of epilepsy did not differ significantly between the generalized $\&$ the partial epilepsies.

Of the 21 patients with partial epilepsies, 17 had simple partial unprovoked seizure as the initial seizure type. Comparing different groups of epileptic seizures (simple partial, complex partial \& generalized), a significant association was found between an initial simple partial unprovoked seizure $\&$ a positive history of CFC in the childhood [Odds ratio: 8.05 (95\% CI 2.88$\left.22.45),\left(c^{2}=15.86, d f=1, p<0.001\right)\right]$. No significant association was found between types of CFC \& the characteristics of the adult -onset epileptic event, possibly due to the small number of patients in each group. The age of onset of epilepsy \& family history of seizures were not found to be significantly associated with a history of CFC in childhood.

\section{Discussion:}

Generalised epilepsies are more common than partial epilepsies in adult-onset epilepsies. Child with $\mathrm{CFC}$ has a genetic predisposition to convulsions in association with fever due to inheritance of a low seizure threshold. ${ }^{14}$ Partial epilepsies were significantly associated with a history of CFC in our study. Perhaps, those genetically susceptible of CFC in childhood are more prone to develop partial epilepsies in adulthood or fever may act as a trigger factor that unmasks a preexisting tendency to epilepsy which may later manifest itself with febrile seizures. We also found a significant association between a possible history of CFC $\&$ initial simple partial unprovoked seizures in adulthood. Associations between complex CFC \& partial unprovoked seizures have been reported in the literature suggesting an underlying brain pathology common to both. ${ }^{15}$ Consistent risk factors for the development of unprovoked seizures following a CFC include a family history of epilepsy, complex features of CFC \& presence of neurodevelopmental abnormalities present from birth. ${ }^{16}$

Children with complex CFC have reportedly a higher risk of unprovoked seizures than children with simple CFC. The majority (87\%) of the CFC in the present study were of simple type. Although the frequency of those with a history of simple CFC is more in the present study, we found no significant association between the type of the adult-onset epilepsy \& the simple or complex features of the CFC. Using the Rochester epidemiological project records linkage system, Annegers et al ${ }^{17}$ found that 32 of the 687 children with a first CFC 
developed subsequent unprovoked seizures. ${ }^{16}$ Sixteen were partial $\&$ sixteen were generalized onset seizure. The incidence of both types of seizures were significantly higher than expected in the Rochester population but the morbidity ration for partial epilepsies was greater than that of the generalized onset seizures. ${ }^{16}$ By ten years of age, there were five fold more children with unprovoked seizures than expected in the Rochester population. In the follow up of their patients, the incidence of unprovoked seizures was still five times the general population at the age of 20 years or older. ${ }^{16}$

In the study by Trinka et al on 113 adult patients with epilepsy, the majority of them developed epilepsy after age sixteen. ${ }^{17}$ The relatively high rate of prior $\mathrm{CFC}$ in our study is not in agreement with the literature. ${ }^{16,18}$ This can be because of a selection bias in a hospital based study. This is the inherent weakness of such studies.

In a recent retrospective study on 109 epileptic patients with prior CFC, Saltik et al suggested that some characteristics of the CFC may reflect the type of epilepsy that subsequently develops. ${ }^{9}$ The result of the study by Trinka et al support the view that prolonged \& lateralized $\mathrm{CFC}$ are associated with temporal lobe epilepsy, whereas brief \& generalized CFC are probably an age dependent expression of seizure susceptibility. ${ }^{17}$

Both CFCs \& epilepsies are regarded as genetic in origin. Generalized epilepsies with febrile seizures (FS) plus (GEFS+) is also a genetic syndrome characterized by heterogeneous epilepsy phenotypes including CFC \& mild to severe generalized epilepsies. ${ }^{19}$ However, partial epilepsies occur rarely in this setting. ${ }^{20}$

According to the Western literature ${ }^{21}$, partial seizures are the most common seizure disorders in adult. In India, however, generalized seizures outnumber other types of seizures. ${ }^{22}$ We know much less about the mechanisms underlying partial seizure disorders than we do about generalized epileptogenesis. ${ }^{21}$

By all indications from our study, the significant association between history of CFC \& occurrence of partial epilepsies warrants more investigations for better understanding the mechanism \& underlying causes of unprovoked partial epilepsies as well as the possible underlying genetic factors common in both the CFC \& partial epilepsies in the affected probands.

\section{Acknowledgement:}

We thank Dr. Md. Rafiqual Islam and Dr. Kanuj Kumar Barmon for providing the data and references.

\section{References:}

1. Berg AT, Shinnar S, Hauser WA, Leventhal JM. Predictor of recurrent febrile seizure; a metaanalytic review. J Pediatr 1990; 116: 329-37.

2. Consensus statement febrile seizures. Long term management of children with fever- associate seizures. Pediatrics 1980; 66: 1009-12.

3. Wallace SJ. The child with febrile seizures. London: John Wright; 1988: 109-26.

4. Nelson KB, Ellenberg JH. Predictors of epilepsy in children who had experienced febrile seizures. N Engl J Med 1976; 295: 1029-33.

5. Annegers JF, Hauser WA, Elveback LR, Kurland LT. The risk of epilepsy following febrile convulsions. Neurology 1979; 29: 297-303.

6. Verity CM, Jean G. Risk of epilepsy after febrile convulsions. BMJ 1991; 303: 1373-6.

7. Bharucha NE, Bharucha EP, Bharucha AE. Febrile seizures, Neuroepidemiol 1991; 10: 138-42.

8. Trinka E, Unterrainer J, Haberlandt E, Unterberger I, Niedermuller U, et al. Childhood febrile convulsions- which factors determine the subsequent epilepsy syndrome! A retrospective study. Epilepsy Res 2002; 50: 288-92.

9. Saltik S, Angay A, Ozkara C, Demirbilek V, Dervent A. A retrospective analysis of patients with febrile seizures followed by epilepsy. Seizure 2003; 12 : 211-6.

10. National Institute of Health. febrile seizures; Long term management of children with fever-associate seizures. Summery of an NIH consensus statement. BMJ 1980; 281: 277-9.

11. Fishman M A. Febrile seizures. In: McMillan JA, De Angelis CD. eds. Oski's Paediatrics: principles \& practice. Philadelphia: Lippincott William \& Willkins; 1999: P. 1949-51.

12. Commission on classification and terminology of the International League Against Epilepsy. Epilepsia 1981; 22: 489-501. 
13. Commission on classification and terminology of the International League Against Epilepsy. Proposal for revised classification of epilepsies and epileptic syndromes. Epilepsia 1989; 30: 38999.

14. Knudsen FU. Febrile seizures treatment and outcome. Brain Dev 1996; 18: 438-49.

15. Hesdorffer DC, Hauser WA. Febrile seizures and the risk of epilepsy. Bran TZ, Shirnar S. eds. Febrile seizure. San Diego: Harcourt; 2002: p.63.

16. Annegers J F, Hauser W A, Shirts S B, Kurland L T. Factors prognostic of unprovoked seizures after febrile convulsions. N Engl J Med; 1987; 316: 498-9.

17. Trinka E, Unterrainer J, Haberlandt E, Unterberger I, Niedermuller U, et al. Childhood febrile convulsions-which factors determine the subsequent epilepsy syndrome!- A retrospective study. Epilepsy Res 2002; 50: 288-92.

18. Sapin D Leitner Y Harel S, Kramer U. Unprovoked seizures after complex febrile convulsions. Brain Dev 2000; 22: 484-6.

19. Scheffer I F, Berkovic S F. Generalized epilepsy with febrile seizure plus. A genetic disorder with heterogeneous clinical phenotype. Brain Dev 1997; 120: 479-90.

20. Singh R, Scheffer I E, Crossland K, Berkovic S F. Generalized Epilepsy with febrile seizure plus; A common childhood-onset genetic epilepsy syndrome. Ann Neurol; 1999; 45: 75-81.

21. Chang BS, Lowenstein DH. Epilepsy. N Engl J Med; 2003; 349: 1257-66.

22. Ray BK, Bhattacharya S, Kundu TN, Saha SP, Das SK. Epidemiology of epilepsy- India perspective. J Indian Med Assoc 2002; 100: 322-6. 